\title{
NEW SOFTWARE SUPPORTING TEACHING OF SIMULINK FOR FULL-TIME CURRICULUM
}

\author{
Karel Perutka \& Aneta Hribnakova
}
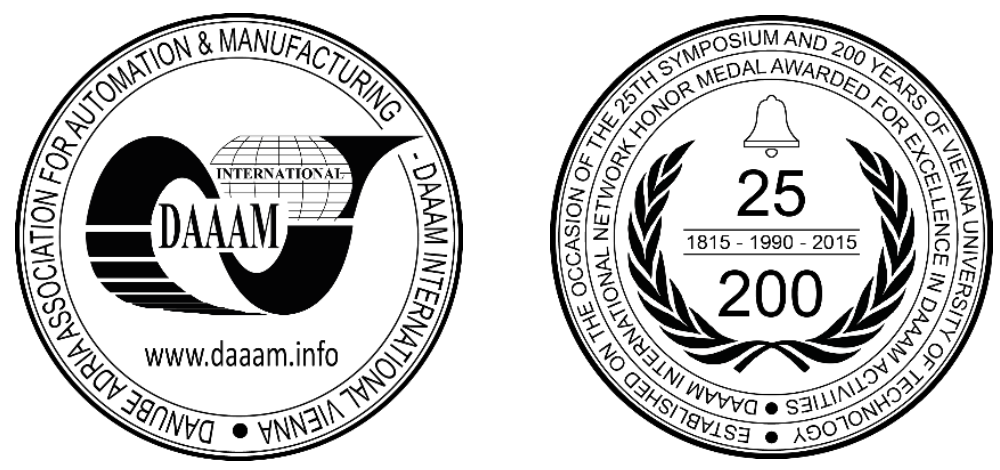

This Publication has to be referred as: Perutka, K[arel] \& Hribnakova, A[neta] (2017). New Software Supporting Teaching of SIMULINK for Full-time Curriculum, Proceedings of the 28th DAAAM International Symposium, pp.00790086, B. Katalinic (Ed.), Published by DAAAM International, ISBN 978-3-902734-11-2, ISSN 1726-9679, Vienna, Austria

DOI: $10.2507 / 28$ th.daaam.proceedings.010

\begin{abstract}
This paper deals with the environment of the program MATLAB - SIMULINK. The paper describes the new software created in purpose to support the teaching of the subject called SIMULINK. It contains the description of the program, the specification of the work with the program from the very beginning and the explanations of the several basic blocks, which are commonly used when studying this subject. Theoretical part mainly analyses already existing teaching supports and it tries to explain the program to the user, who deals with SIMULINK for the first time. Practical part mainly focuses on the description of the application, which is created as the support for teaching the subject MATLAB and SIMULINK, specifically the part of subject dealing with Simulink. The software was used during teaching and positively evaluated by students.
\end{abstract}

Keywords: MATLAB; SIMULINK; Educational Tool

\section{Introduction}

The contemporary conception of education is in a large measure based on accentuation of the particular individual's needs in relation to his role in society. Each individual can fully develop his capabilities only in society able to learn and to response to changes in a flexible manner. Education as a demonstration of socio-cultural and economic dimension is in all aspects and fields interconnected with the utilization of modern technologies [9].

The last research in modern education incorporates the usage of cartoons as the specific form of presentation that attracts student more than classical books or lectures.

Are the cartoons another educational tool or aid and why? The childhood of a person is shaped according to the conditions of his/her community. However, the childhood in our technology-based era is highly overwhelmed by the ubiquitous communication devices. As a pioneering type, television achieves in grabbing children's attention by using its multi-colored and animated world. What is more, cartoons provide the audience a great load of new ideas, allowing them to enrich their dream world as well as to improve their vocabulary and learn new games. These developments are then turned to permanent behaviors [10].

The usage of specific tools, mostly games, is also important for teaching people with some learning difficulties. 
ICT educational tools can play an essential role in the cognitive development and inclusion of disabled people. The increasing adoption of ICT has created the conditions for significant improvements in the ability to acquire, produce and exchange information. This is of particular importance because better education and fluency in ICT meets the objectives of e-inclusion. Starting from the mathematics learning difficulties of motor-impaired people, it was argued that in this field specific educational tools are propaedeutic to a more informal learning approach based on serious games. For disabled people ICT educational tools can be in many cases essential to overcome motor, perceptual or cognitive difficulties that prevent or at least make difficult their inclusion in the society [11].

There exist the concept of the inverted classroom and it was implemented for example to educate MATLAB in chemical process control. Integrating mathematical simulation software such as MATLAB in chemical engineering curricula has been attracting widespread interest during recent decades, especially for courses involve process design. Research has been conducted in comparing different software packages including POLYMATH, Mathcad, MATLAB, Mathematica, Maple and Excel for educational use in chemical engineering, and results indicated that MATLAB is especially excellent for demonstrating matrix operations and multi-variable iterative processes. In addition, MATLABbased simulation has been verified for promoting deeper understanding of process modeling techniques [16].

MATLAB is widely used software at technical universities to create and practice technical solution of several technical tasks [8].

Identification of system is one of such tasks. For example, the identification of continuous-time (CT) models is a problem of considerable importance that has applications in virtually all disciplines of science. It is therefore important to introduce data-based continuous-time model identification to engineering students in the user friendly form. For that purpose, Continuous-Time System Identification (CONTSID) toolbox and its graphical user interface were created in MATLAB [13]. MATLAB also offers its web server and JAVA implementation. Experiences with MATLAB web server and JAVA implantation were also published [14].

Implementation at overhead power lines using MATLAB is another example. The electrical power transmission is realised in most of the cases by overhead power lines long of hundreds of kilometres and operating at different high voltage levels. The load of these overhead power lines is widely varying depending both on the evolution of consumers (the consumers load curve) and on the operating conditions of the power system elements. Therefore, the $400 \mathrm{kV}$ overhead power line was modelled using MATLAB and SIMULINK and the operating conditions were analyzed. The presented model was used in teaching activity during the power grids laboratory lessons for power engineering students of the university curriculum [17].

Next example of educational tool in the area of the electrical engineering is the following one. It is the educational software package called TSCOM (thyristor switched reactive power compensators). It contains simulation models of thyristor switched capacitor and thyristor switched reactor-based static VAR compensator which are two of the shunt flexible AC transmission systems devices. The design was realized using MATLAB and SIMULINK. The proposed package helped to design the practical prototypes for students and researchers [12].

MATLAB application in the area of global navigation satellite systems education is another example. It is used by students in aerospace engineering and was created using Graphical User Interface Design Environment. It highlights the space segment of these navigation systems and concepts such as visibility, ground-tracks and coverage. Using this graphic tool, students can visualize the real position of all satellites in the GPS constellation at any time since its start of operation, analyze the number of satellites that can be visualized from any point in Earth, or study the quality of the navigational solution which depends on the relative geometry of the user and satellites. The tool also allows to perform these studies for a flight between any two points on Earth, or for the user-defined region [18].

Educational games help to increase the motivation of the students and to enhance their learning performance. For instance, educational games illustrate the link between theoretical methods presented in class and practical applications. There were created games in MATLAB in purpose to help teaching, such as the one created at the University of Stuttgart to practice the knowledge of advanced automatic control, the airplane behavior [12].

It is important to have the software tool that practices the knowledge of this software. For that purpose and directly according to the contents of the labs from SIMULINK, the new software supporting teaching of SIMULINK was created and it is described in this paper. The paper is organized in the following way. After introduction part, the short description of MATLAB and SIMULINK software is presented. It is followed by the description of the newly created application with depiction of main dialog and selected practical example. Finally, the new application is evaluated.

\section{Brief intro about MATLAB and SIMULINK}

\subsection{MATLAB in general}

The name MATLAB originated from two English words, matrix and laboratory, which means "matrix and lab". MATLAB is the program environment that allows us to count a variety of mathematical operations, it can handle with vectors and matrices, plot charts, and create user interface applications [1], [2].

The program itself contains predefined features that user calls from the shortcut menu. MATLAB is mainly used for scientific and technical purposes or in colleges for teaching purposes. 


\subsection{MATLAB environment}

When the MATLAB is started, the basic window will be displayed and divided into several main sections. The sections are:

Menu - the main menu bar at the top of the window which contains three tabs - Home for basic file operations, variables, help browser, and others, Chart Style Plots and Apps where you can download various additional applications to ease the work with MATLAB [4].

Current Folder - displays list of all files in the current folder, MATLAB is the default folder that is displayed. The files in this window are triggered by double-clicking with the mouse, the file opens in the given editor according to its extension.

Command Window - A window into which the user enters commands, runs functions and scripts, and results are displayed [7].

Workspace - this window is empty when MATLAB is started, and then all the variables and their values that were used during the work with MATLAB are displayed. With more variables, there is better orientation using Workspace window than just using the command window.

Command History - A list of commands that were used during last MATLAB calls including the date and time, the history of the commands can be easily reused by double-clicking on the command or set of commands by the mouse. The Command History can be saved in the new source file $[1,4,8]$.

\subsection{SIMULINK in general}

The word SIMULINK comes from two English words - simulation and link. It is the main extension of the MATLAB build-in environment, and it was designed to model and simulate dynamic systems, so it is necessary to have MATLAB installed to work with SIMULINK. While commands are entered in the Command Window in MATLAB, SIMULINK combines blocks that have different functions. User can create his/her own blocks or edit existing blocks. To work in SIMULINK, it is appropriate for the user to have minimal basic knowledge of MATLAB [2, 3]. Other good research papers were published [3], [5], which might be transformed for educational purposes.

\subsection{Running SIMULINK}

SIMULINK can be started in several ways. For example, by typing the text "simulink" in the MATLAB Command Window and pressing the ENTER key. Another option to open SIMULINK is via the Simulink Library button, which is located in the main ribbon section and SIMULINK starts as was described before. After SIMULINK calling new window appears, where all the standard SIMULINK libraries are located, as well as those that the user had additionally installed or created by himself. Libraries have blocks sorted alphabetically, according to their area of use.

\subsection{SIMULINK Environment}

The SIMULINK window is divided into two main sections. In the left part of the window, there are all available libraries and in the right part of the window, there are the blocks that the selected library contains. Blocks can be searched either by the category they are divided into, or if you know at least part of the name, go to the search box at the top of the window in the Enter search term edit box. This window contains two important buttons, namely the creation of a new model and the opening of existing model, located at the top of the window on the left.

\subsection{Creating new model}

At the beginning, you need to open new window to create a model. This can be done in several ways. The first option is to click on File $\rightarrow$ New $\rightarrow$ Simulink Model in the MATLAB environment, the second one is by clicking the SIMULINK icon with the "+" sign located on the right side in the library window, and the last method is, as in many Microsoft Windows programs, shortcut $\mathrm{Ctrl}+\mathrm{N}$. After each of these operations, the blank window opens, where you can create the new model. The model is simply created by dragging the blocks from the Simulink Library Browser to the desktop of the window that is currently opened. If you need to use a block multiple times, you can simply copy it by right-clicking and dragging it, holding Ctrl and dragging, or copying using the Ctrl $+\mathrm{C}$ and $\mathrm{Ctrl}+\mathrm{V}$ shortcut keys. Within one model, you cannot find blocks with the same name, so the same blocks are created with names like "Block, Block1, Block2, etc." You can simply rename the block by clicking on its name and overwriting it. The interconnection of blocks is done by dragging the mouse from the output of one block to the input of another block, or vice versa. If you need to connect a block to an existing connection, simply drag the input / output of this block to the junction and automatically create a new node.

Double-clicking on a block opens a dialog for parameters setting. Each block has specific settings. The model starts after clicking the Run button at the top of the window. The simulation time can also be set in the Simulation stop time edit box. 


\subsection{Creating subsystems}

As an example for creating a subsystem, there is a model for calculating the roots of the quadratic equation found also in the newly created application. First, it is necessary to create the entire model and then drag the mouse or hold down the Shift key and click on the blocks to mark the ones to create the subsystem.

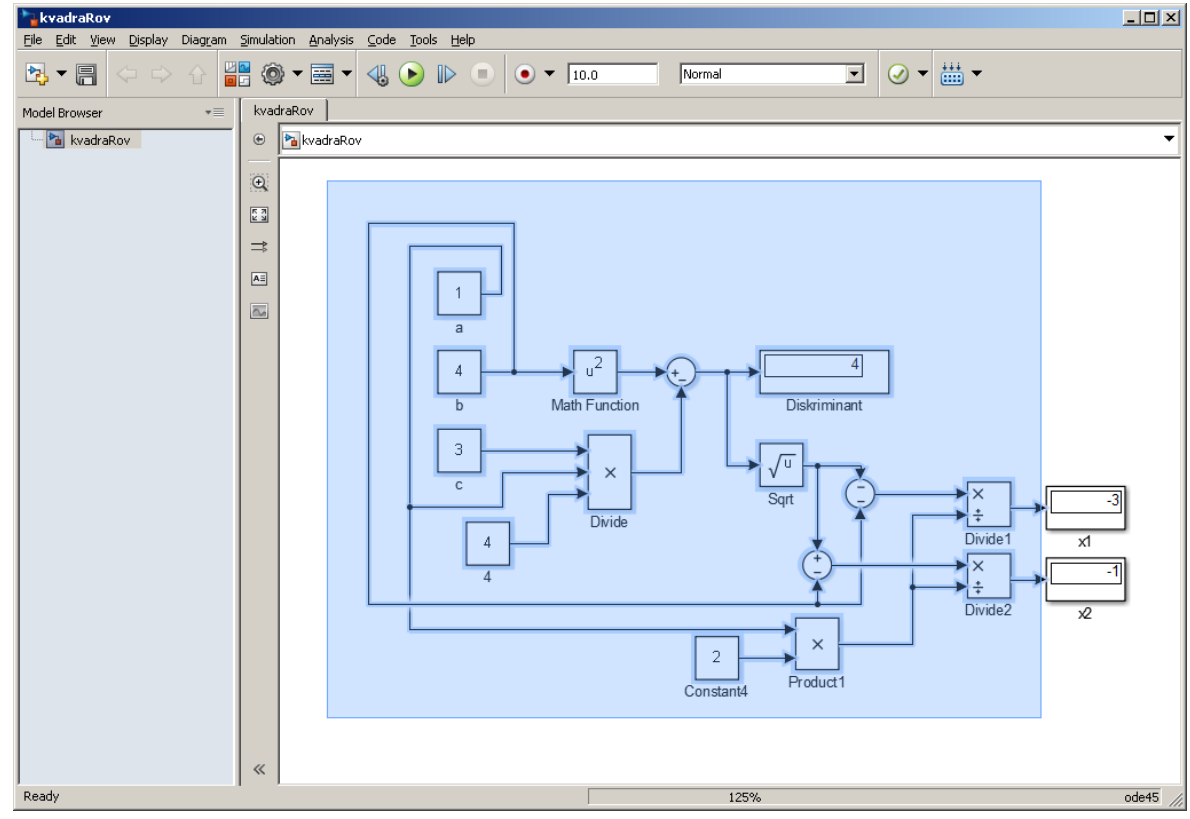

Fig. 1. Marking the blocks in SIMULINK model

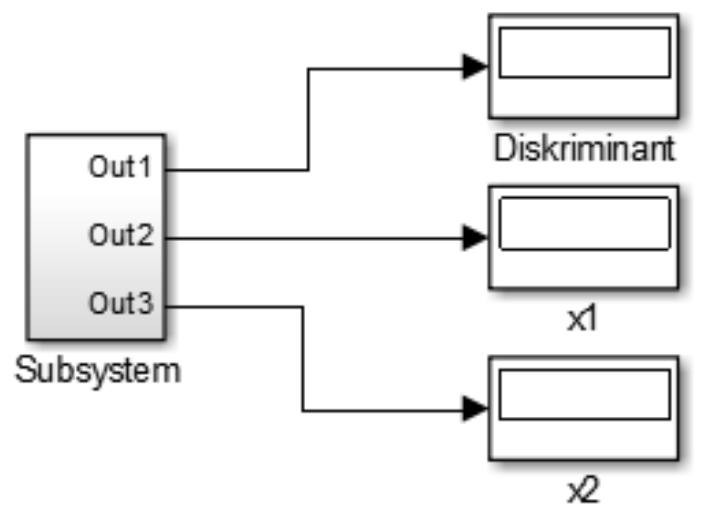

Fig. 2. The newly created subsystem from the marked blocks

\section{Newly created application}

\subsection{Creating new GUI for application}

The main dialog of the application contains five objects. There are two Static Text objects, one Axes object and two Push Buttons objects [6].

Object Static Text displays static text, which is in the form of the title and subtitle of the application, after doubleclicking the mouse, the Property Inspector window will appear to set almost all parameters.

For static text, it's usually enough to set the size, font and color of the text, and last but not least, write the text itself that the object will display.

The Axes object in the created dialog is used to display the image, specifically the faculty logo. It does not generate any code into source file, so the command displaying the picture, must be written manually. 


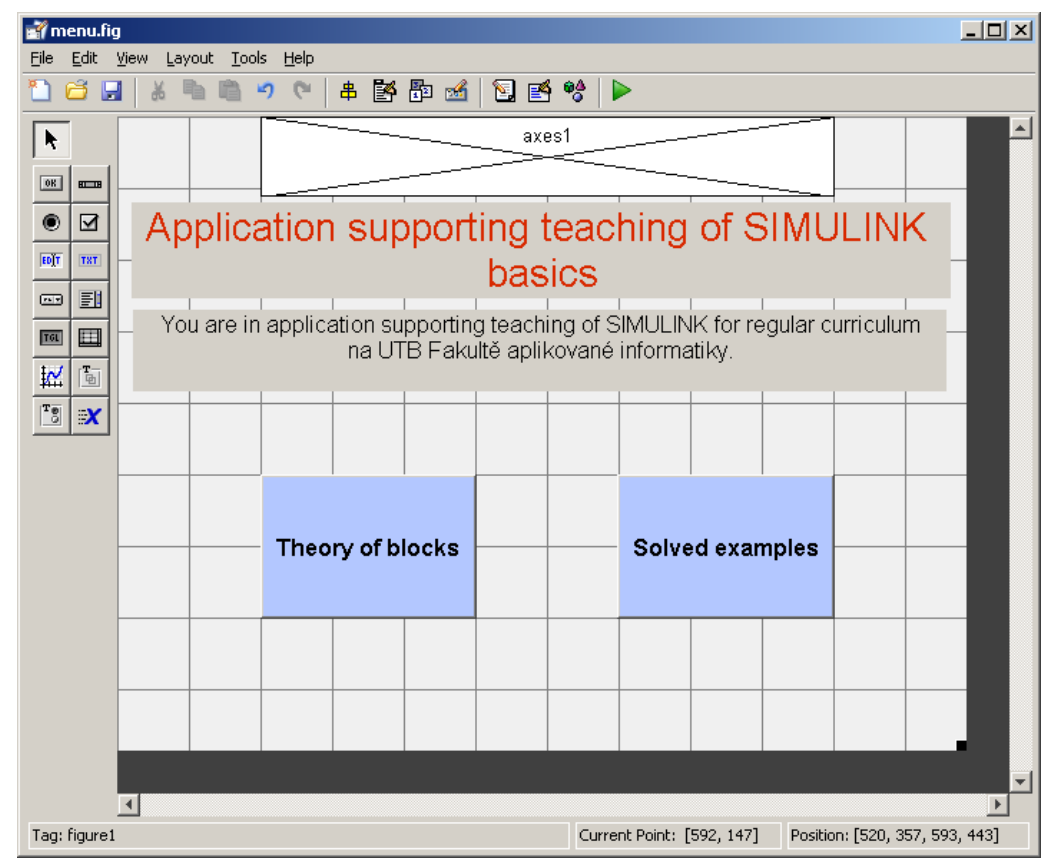

Fig. 3. The main dialog layout of the newly created application

\subsection{Blocks - applications}

The bloky.fig file contains two Static Text objects, the title of the application and the title of the current slide, and five Push Button objects, one of which refers back to the main menu, and four refer to libraries. Button functions are the same as in the previous main menu. The portion of the code is automatically generated and the rest is manually completed.

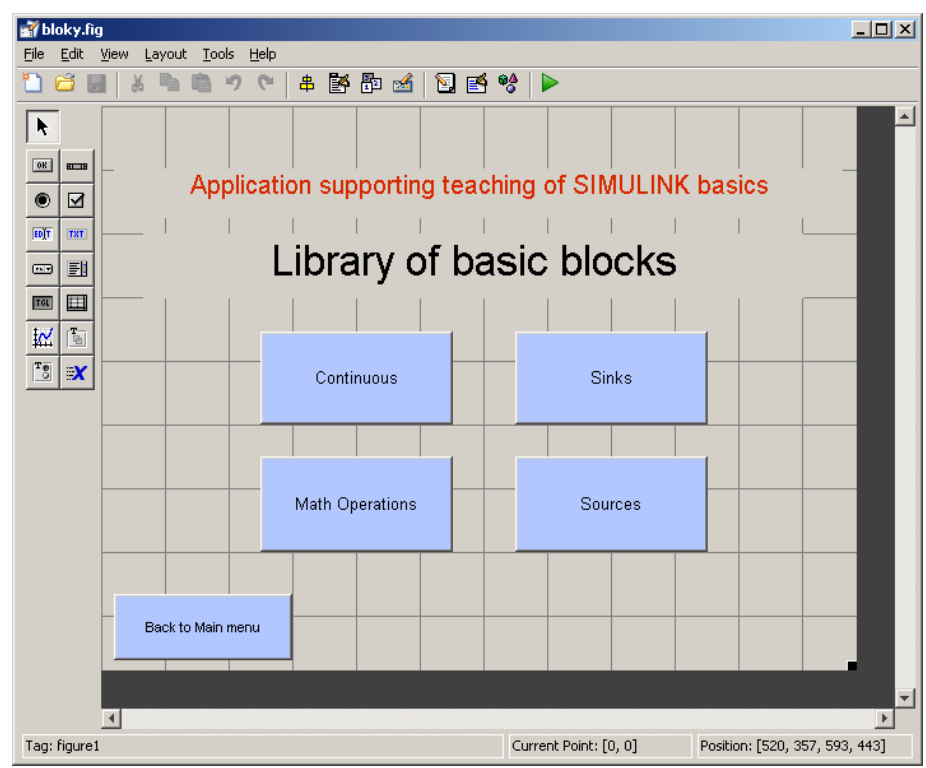

Fig. 4. The scheme of blocks describing and practicing most commonly used blocks

\subsection{Examples - applications}

The priklady.fig file contains Static Text and Push Button objects. One button moves back to the main menu and the other displays the given example. Clicking one of the examples closes the current window and opens the window with the selected example. As the first example of the window with examples, the input is in Static Text object and there are also two Push Buttons, one returns to the previous dialog and the other refers to the next figure. The following objects are the dialog: the Axes object where you can see an example of solved task and two push-buttons, one returns to the main menu and closes the current window, and the other opens an example in SIMULINK, so the .slx file, but the current window remains open. 


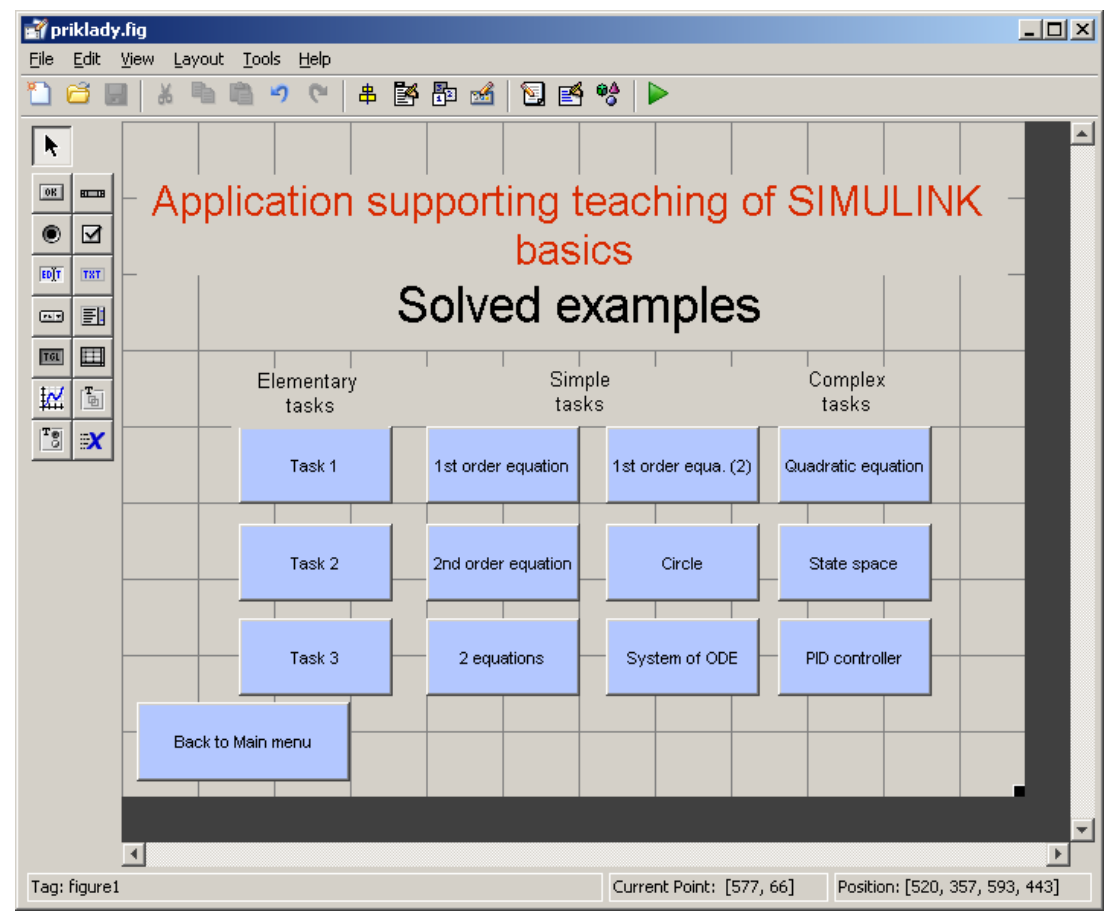

Fig. 5. GUI layout of examples dialog

When a user selects one of the buttons in the "Basic tasks" section, a simple entry dialog is displayed to check that he knows where to find the blocks, how to set them and then link them. For example, there is a simple mathematical example $\sqrt{ }(6-12+22)$, and when it is called, a picture is displayed, in which is described how to create the scheme. This image also contains the "Solution in SIMULINK" button, which opens the completed schema in the SIMULINK environment.

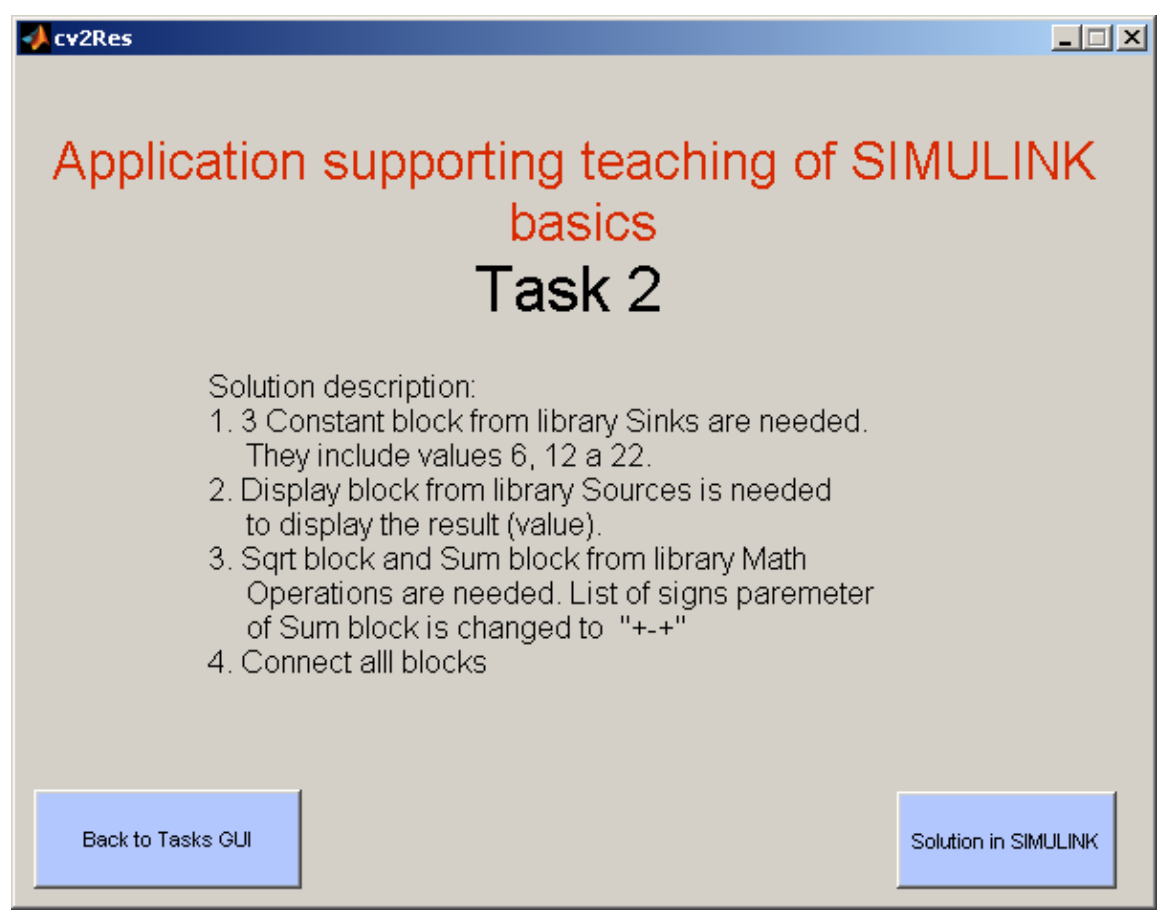

Fig. 6. GUI describing how to solve selected task

Clicking on the "Solution in SIMULINK" button opens this schema in SIMULINK, where it can be edited and run. The second example in this section is focused on the first-order differential equation, it is otherwise specified and contains some other blocks, such as the square root block. 
Application supporting teaching of SIMULINK basics

1st order ordinary differential equation

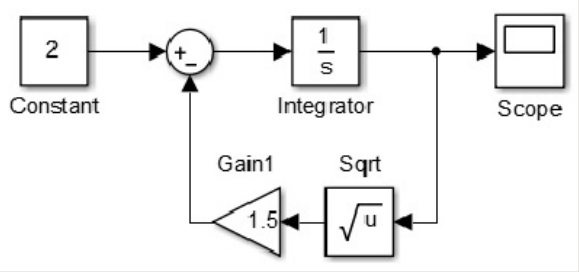

Back to Task GUI

Solution in SIMULIN

Fig. 7. Scheme used to solve the differential equation.

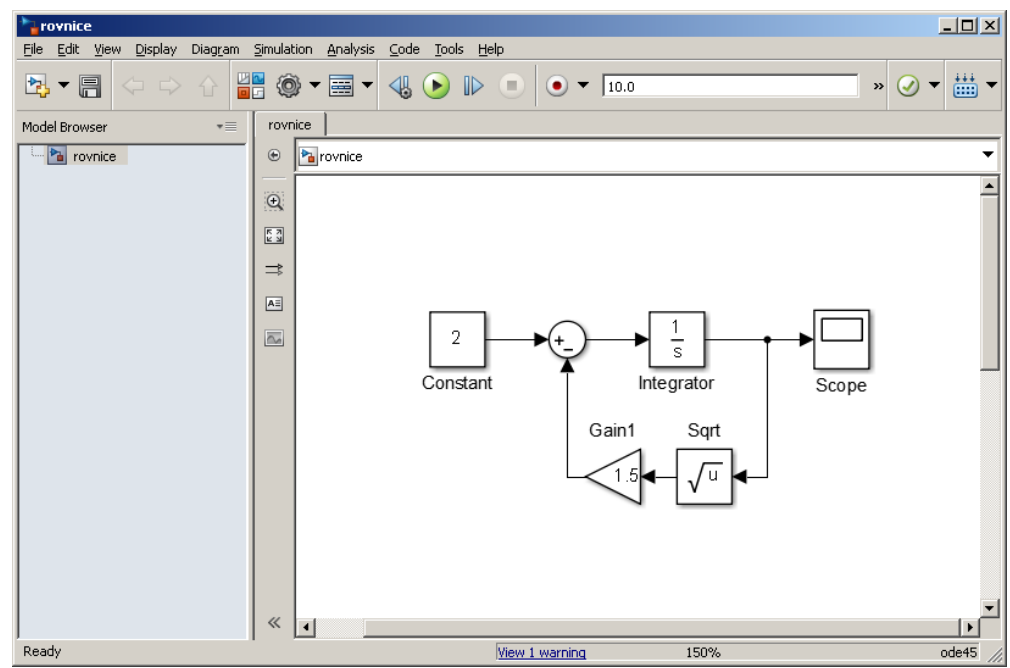

Fig. 8. Model used to solve the differential equation.

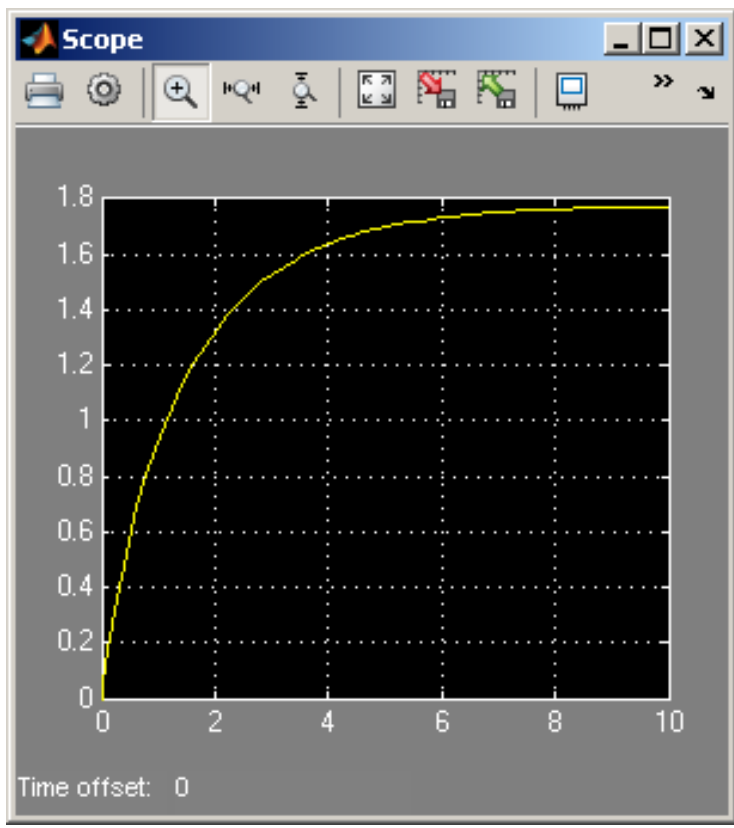

Fig. 9. Solution of differential equation. 


\section{Evaluation of created solution}

The created educational tool became the part of new modern educational aids in according to the modern strategy of teaching that implements the lectures and practices in the attractive form. The students confirm that they are more attract to studies. The tests that verified the SIMULINK knowledge of students confirmed the better knowledge of students who worked with this new application in comparison to those who did not use it. The issue of the paper was to solve the problem - to find something to increase the knowledge of SIMULINK usage at the faculty in the given curricula. It is important to understand the application functionality and to have the knowledge of SIMULINK. The contents of the teaching aid is limited to SIMULINK applications used during classes only.

\section{Limitations}

Although the paper has reached its aims, there were some limitations. First, because the teaching tool is new, it was verified only by small group of students who was attending the classes at the laboratories. Therefore, it is necessary to use it for some years to generalize the result and to find what to improve and enlarge. Second, the content of the created programme was prepared for the given curriculum, so it is necessary to modify or enlarge it in purpose to use the new programme by users from other university.

\section{Conclusion}

The paper presented newly created application in SIMULINK that was created for practicing the knowledge of SIMULINK usage in the attractive way. There was no specific tool practicing the lectures from the area of SIMULINK at my faculty. It was the main problem. This problem was solved by new project, and lead to the creation of the new tool in SIMULINK. Before the problem solution, the necessary introduction to SIMULINK was done and this was followed by the creation of new application practicing the student knowledge of Simulink and it was positively evaluated by students. Students used it before final test from SIMULINK. It covers the whole introductive course to SIMULINK and examples how to solve set of algebraic equations, differential equation, the quadratic equation, drawing circle in SIMULINK etc. Future work will be oriented on more complex enlargement of the newly created application.

\section{References}

[1] Perutka, K.(2005). MATLAB - Basics for students of automation and IT, UTB ve Zline, ISBN 80-7318-355-2, Zlin.

[2] Dušek, F. (2001) Simulink - Introduction for users, University of Pardubice, ISBN 80-7194-273-1, Pardubice.

[3] Haskovic, D., Katalinic, B. \& Kukushkin I. (2015). Role of the Adviser Module in the Hybrid Assembly Subordinating Control Structure, Procedia Engineering, Volume 100, ISSN 1877-7058, pp. 1706-1713.

[4] Zaplatílek, K. \& Doňar ,B. (2005). MATLAB for beginners. BEN - technical literature. ISBN 80-7300-175-6, Brno.

[5] Gastermann, B., Stopper, M., Kossik, A. \& Katalinic, B. (2015). Secure Implementation of an On-premises Cloud Storage Service for Small and Medium-sized Enterprises, Procedia Engineering, Volume 100, ISSN 1877-7058, pp. 574-583.

[6] Hribnakova, A. (2017). Application design to support Simulink teaching for full-time curriculum. Thesis. Tomas Bata University in Zlin, Zlin

[7] Kozák, Š. Kajan, S. (1999). MATLAB-SIMULINK I. Bratislava: Slovak University of Technology in Bratislava, ISBN 80-277-1213-2, Bratislava.

[8] Kupka, L. (2006). MATLAB Simulink Introduction for users . SOŠ a SOU Lanškroun, ISBN 978-80-239-8871-0, Lanškroun.

[9] Dostál, J., Serafín, Č., Havelka, M. \& Minarčík, J. (2012). Assessment of Quality of Material Educational Tools for Technical Education, Procedia - Social and Behavioral Sciences, Volume 69, ISSN 1877-0428, pp. 709-718.

[10] Özer, D. \& Avc1, İ.,B.. (2015). Cartoons as Educational Tools and the Presentation of Cultural Differences Via Cartoons, Procedia - Social and Behavioral Sciences, Volume 191, ISSN 1877-0428, pp. 418-423.

[11] Curatelli, F. \& Martinengo, C. (2012). Design Criteria for Educational Tools to Overcome Mathematics Learning Difficulties, Procedia Computer Science, Volume 15, ISSN 1877-0509, pp. 99-102.

[12] Münz, U., Böhm, Ch., Eck, J., Reble, M., Schumm, P. \& Allgöver, F. (2010). A Matlab-Based Game for Advanced Automatic Control Education, IFAC Proceedings Volumes, Volume 42, Issue 24, ISSN 1474-6670, pp. 140-145.

[13] Garnier, H. (2011). Teaching Data-based Continuous-time Model Identification with the CONTSID Toolbox for Matlab, IFAC Proceedings Volumes, Volume 44, Issue 1, ISSN 1474-6670, pp. 6373-6378.

[14] Hölttä, V. \& Hyötyniemi, H. (2003). Experiences with Matlab Web Server and Java, IFAC Proceedings Volumes, Volume 36, Issue 10, ISSN 1474-6670, pp. 47-52.

[15] Gelen, A. \& Yalcinoz, T. (2010). An educational software package for Thyristor Switched Reactive Power Compensators using Matlab/Simulink, Simulation Modelling Practice and Theory, Volume 18, Issue 3, ISSN 1569190X, pp. 366-377.

[16] Li, X. \& Huang, Z.(J.) (2017). An inverted classroom approach to educate MATLAB in chemical process control, Education for Chemical Engineers, Volume 19, ISSN 1749-7728, pp. 1-12.

[17] Baloi, A., Pana, A. \& Molnar-Matei, F. (2015). Advantages of Using MatLab Simulink in Laboratory Lessons on Operating Conditions of Overhead Power Lines, Procedia - Social and Behavioral Sciences, Volume 191, ISSN 1877-0428, pp. 179-184.

[18] Lanagran-Soler, F., Vazquez, R. \& Arahal, M.R. (2015). A Matlab Educational GUI for Analysis of GNSS Coverage and Precision, IFAC-PapersOnLine, Volume 48, Issue 29, ISSN 2405-8963, pp. 93-98. 